\title{
Can Investors Profit from Gender Heterogeneity among the Prophets?*
}

\author{
Peter de Goeij ${ }^{\dagger} \quad$ Kristien Smedts ${ }^{\ddagger}$
}

June 30, 2008

\begin{abstract}
We document that buying assets for which the difference in average recommendation between male and female analysts is small and female analysts are more optimistic, yields significant net annual returns of 3.2 percent after controlling for market risk, size, book-to-market and price momentum effects. The finding is robust to different stock selection criteria. In addition, correcting for firm size effects shows that the strategy yields comparable results for the subset of large firms. Furthermore, we show that the outperformance is robust to regulatory changes in September 2002, while market wide liquidity exposure cannot explain the documented outperformance.
\end{abstract}

*We thank Esther Eiling and Ralph Koijen for their help to collect the data, Thomson Financial for the I/B/E/S recommendation data and CRSP for the return data. We thank Frank de Jong and Bas Werker and seminar participants at Tilburg University and Robeco Quantitative Strategies for their comments and suggestions that helped improve the paper.

$\dagger$ Tilburg University, Department of Finance, CentER for Economic Research, P.O. Box 90153, 5000LE Tilburg, The Netherlands. Email: p.c.degoeij@uvt.nl, phone: (+) 31 (0)13 4662083, fax: (+) $31(0) 134662875$.

$\ddagger$ Catholic University of Leuven, AFI, Naamsestraat 69, 3000 Leuven, Belgium. Email: kristien.smedts@econ.kuleuven.be, tel: (+) 32 (0)16 326739, fax: (+) 32 (0)16 326732. 


\section{Introduction}

We show that investors can profit from exploiting gender heterogeneity in the recommendation issuing process of financial analysts. Whether to profit from publicly available information is an intensely debated issue. Semi-strong form market efficiency implies that investors should not be able to make profits based on publicly available information. Yet, the large sums of money spent on security analysts on Wall Street suggest that practitioners and investors are convinced about the value added of these recommendations.

Given such opposing views, a large empirical literature analyzes the value of analysts' recommendations. Early studies by Cowles (1933), Bidwell (1977) and Diefenbach (1972) conclude that the advice of security analysts does not generate abnormal returns. Subsequent research by Stickel (1995) and Womack (1996) suggests however that a recommendations-based investment strategy could be profitable. Barber et al. (2001) show that analyst recommendations can be used to construct a profitable investment strategy that involves daily portfolio rebalancing, but that the associated transaction costs wipe out the potential profits. Jegadeesh et al. (2004) find that the level of recommendations does not really add value when used in addition to other well-known predictor variables. They do find however that the quarterly change in the consensus recommendation has explanatory power to predict future returns.

Security analysts process a large amount of information in order to issue recommendations on companies. Such a recommendation is not a simple valuation decision, but is the result of a complex and individual (possibly subjective) decisionmaking process incorporating the risk-return characteristics of the financial instrument being examined. ${ }^{1}$ Indeed, the literature documents several biases which implies that the recommendation issuing process is not just rational, but also driven by behavioral motives. First, there is an upward bias in the distribution of recommendations. Analysts are reluctant to issue negative reports, resulting in (overly) optimistic recommendations (see among others, Barber et al. (2007), Lin et al. (2005) and Chen and Matsumoto (2006)). Second, security analysts have the tendency to herd. Although herding can potentially be information-driven, a

\footnotetext{
${ }^{1}$ For example, on their website Smith Barney notes that their rating system is absolute in nature, with each recommendation being the result of an expected total return - risk rating (see http://www.smithbarney.com/research/rating_system.html).
} 
recent study by Jegadeesh and Kim (2007) finds that recommendation revisions are partly driven by analysts' desire to herd with the group. The herding behavior of analysts found in Welch (2000), Hong et al. (2000) and Clement and Tse (2005) could therefore, at least partly, be the result of such imitation-behavior. Despite the evidence that financial analysts do not always behave rationally, to our knowledge, there does not exits a study that shows that the recommendation issuing process is gender specific.

Nevertheless, there exists a large literature showing that the decision making process of women significantly differs from that of men $^{2}$. Among others, Jianakoplos and Bernasek (1998) and Sunden and Surette (1998) find that women are more risk averse than men, leading them to take less financial risk. In addition, Cadsby and Maynes (2005) find that women show less heterogeneity in their decisions than men. Other studies have shown that gender specific behavior among investors causes differences in performance between men and women. Barber and Odean (2001) show that men trade more than women lowering their net returns by almost 1 percent more a year than women. A recent study by Niessen and Ruenzi (2007) investigates gender differences among professional investors. Although they document similar average performance of female and male mutual fund managers, female managers are more risk averse, trade less and follow less extreme and more consistent investment styles. This study differs from these latter studies as we do not investigate gender differences among investors, but we study gender heterogeneity in the advice that is given to investors.

To our knowledge, this study is the first to investigate whether gender heterogeneity among analyst recommendations can be exploited by investors. We focus on the profitability of investment strategies that exploit differences between the gender specific consensus recommendations. The consensus is a natural choice as it takes into account the information implicit in the recommendations of all the analysts following a particular stock. We follow an investor-oriented, calender-time approach similar to Barber et al. (2001). This permits us to directly measure the abnormal gross returns and to estimate portfolio turnover and the associated transactions costs.

For each asset we calculate the Gender Consensus Difference $(G C D)$ defined

\footnotetext{
${ }^{2}$ Croson and Gneezy (2004) synthesize studies on preference differences between men and women.
} 
as the male consensus recommendation minus the female consensus recommendation. A positive $G C D$-rating implies that male analysts issue on average more favorable recommendations than female analysts. Alternatively, when an asset's $G C D$-rating is negative, female analysts issue on average more favorable recommendations than male analysts. We track the investment performance of firms grouped into portfolios according to their $G C D$-rating using monthly portfolio rebalancing.

Our findings can be summarized as follows. We document that buying a portfolio that consists of stocks with a small, but negative $G C D$-rating (i.e. female preferred stocks) results in net abnormal returns of 3.2 percent annually. This result is robust to different stock selection stock selection criteria. In addition, correcting for firm size effects shows that the strategy yields similar results for a subset of large firms only. Moreover, we show that the outperformance is robust to regulatory changes in September 2002 while market wide liquidity exposure cannot explain the documented outperformance.

The remainder of the paper is organized as follows. In Section 2 we describe the data and present descriptive statistics. Section 3 discusses the research design, while in Section 4 we analyze the performance of the gender-based strategy and we study its risk characteristics. In Section 5 we investigate whether our results are robust for different stock selection criteria and particular subsamples of the data. Finally, concluding remarks are presented in Section 6 .

\section{Data and Descriptive Statistics}

For this research we combine data from four different sources. First, we collect the recommendations that are issued by financial analysts. Second, we identify the gender of the analysts. Third, we merge the gender-recommendations database with return data and finally, we download benchmark returns from the website of Kenneth French. ${ }^{3}$

The analyst recommendations are provided by the Institutional Broker Estimate System (I/B/E/S) database, which is part of Thomson Financial. The

\footnotetext{
${ }^{3}$ We thank Kenneth French for making the benchmark returns available.
} 
recommendations encompass the period 1996 - 2006. ${ }^{4}$ Each data record includes information about, among other things, the recommendation, the recommendation date, identifiers for the brokerage house issuing the recommendation and for the particular analyst who issues the recommendation (the surname and first initial). Recommendations are given on a five-point scale. I/B/E/S collects the recommendations and assigns standardized numerical values to them. A rating of 1 reflects a strong buy, 2 reflects a buy, 3 a hold, 4 a sell, and finally a score of 5 corresponds to a strong sell. To allow for a more intuitive interpretation of our results we reverse the ordering of the values, so that more favorable recommendations receive a higher score. We trim the I/B/E/S database by deleting incomplete observations which lack identification of the analyst, the brokerage house the analyst works for, the company that is being followed, the corresponding industry, the recommendation, or the monthly consensus recommendation.

This recommendations' sample is combined with Nelson's Directory of Investment Research (editions 1997 - 2007). Nelson's Directory is a yearly analysts' contact details book and contains an analyst's full name, the brokerage house (s)he is employed for, her/his specialization, and contact information. We use this information to manually match the I/B/E/S analyst identification with the full first name and last name of each analyst. Based on the first name, we determine the gender of each analyst. We rely on a website that contains a program using Google's database to analyze common patterns involving first names. ${ }^{5}$ It determines from popular usage on the web whether a name is more common for a man or a woman. If we are not sure of the gender of the analyst, we check the name and gender by searching the history of the analyst on the internet. We delete observations when there is any ambiguity of the gender. From the 333,492 complete observations in I/B/E/S we are able to match $94 \%$ with the corresponding gender of the analyst. Finally, we trim the database by eliminating analysts covering an unrealistic number of firms (we top off the 99th percentile), and we restrict

\footnotetext{
${ }^{4}$ The I/B/E/S data that we use for our analysis below, has been downloaded in February 2007. A recent paper by Ljungqvist et al. (2007) shows that ex post changes are implemented in the I/B/E/S database. In their Appendix A they show that since February 12, 2007 many, but not all of the changes (anonymizations, alterations and deletions) in the recommendations database have been reinstated. We do not have earlier snapshots of the I/B/E/S database available such as Ljungqvist et al. (2007). Therefore it is impossible to check whether the changes in the database were random accross gender and subsequently how their findings influence the results of this paper.

${ }^{5}$ See http://www.gpeters.com/names/baby-names.php.
} 
our sample to companies covered by at least one male and one female analyst simultaneously.

Next, for each datarecord in the sample, we need the company's stock price information to calculate returns. This information is collected by linking the merged I/B/E/S - Nelson's database with the CRSP database. We take into account the outstanding recommendations of the analysts on the final trading day of each month. Our final sample contains 214,171 newly issued recommendations. Table 1 shows descriptive statistics for this final sample of analyst recommendations. The total sample consists of recommendations of 6,852 unique analysts from 528 brokerage houses covering 4,716 firms. The annual number of recommendations steadily increases, reaching a peak in 2002. From that point onwards, the number of recommendations decreases rapidly, to reach a level at the end of our sample period that is close to the 1997 level. In addition, for the number of firms covered and the number of analysts employed, we observe a similar but weaker trend. The number of brokerage houses is larger in the second half of the sample. Finally, female analysts are clearly a minority as only 17 percent of all analysts in the complete sample are women. Moreover, there is a clear downward trend in the number of female analysts, falling from 16 - 17 percent of the analyst community until 2001 to only 13 percent in 2006. The fact that for every year separately, female representation is lower than in the complete sample indicates that analyst turnover is higher among women than among men. This implies that on average, male analysts are working longer in the industry.

The descriptive statistics of the nature of the recommendations that are issued by the analysts can be found in Table 2 . This table reports the yearly average recommendation, the yearly dispersion of recommendations as measured by the standard deviation of outstanding recommendations. The table also shows a frequency table of the different recommendation signals split by gender. There are no large differences between the average male and female recommendations, neither between the dispersion of the recommendations. There does not seem to be a clear gender effect in the level of recommendations. Only for the years 2000 and 2005 we find that the mean recommendations of male and female analysts is statistically different from each other. For both gender groups, we observe a rather high mean recommendation. This corresponds to the well-documented upward bias in recommendations, with analysts being reluctant to issue negative reports. Several 
studies argue that mixed incentives of analysts lie at the basis of this bias. ${ }^{6}$ The stock market hype surrounding the end of the second millennium even reinforced this bias, as analysts became more positive over time, with a peak towards the year 2000. With bearish markets starting in 2001, this trend reversed, with a subsequent decrease in analysts' ratings. Barber et al. (2007) and Conrad et al. (2007) find the same dynamics and argue that this trend reversal can be the result of a bad performing stock market and/or increased regulatory scrutiny of analysts' activities.

The optimism in recommendations can also be seen from the frequency distribution in Table 2. Until 2001 both male and female analysts issue few Strong Sell and Sell recommendations: combined they cover less than $3 \%$ of all recommendations. From 2002 onwards the number of these negative reports increases to more than $10 \%$ of all recommendations that are issued. Considering the fact that stock markets have been performing very well since 2003, we believe that there has been a structural change in analyst behavior since 2002. For example Conrad et al. (2006) mention that the collapse of technology stocks introduced a sometimes contentious debate on the neutrality of analysts with several Wall Street firms. This introduced increased scrutiny of analysts' practices by the Securities and Exchange Commission and the states attorneys general. Indeed, Barber et al. (2007b) show that in the wake of numerous high-profile corporate scandals (such as those involving Enron, WorldCom, Adelphia, and Tyco) the National Association of Securities Dealers (NASD) proposed rule 2711, which was approved by the SEC on May 8, 2002 and enforced on September 9, 2002. The rule contains a disclosure provision which entails that every brokerage firm is required to disclose in its research reports the distribution of stock ratings across its coverage universe. ${ }^{7}$ In the empirical part below, we investigate whether these regulatory changes affect the results.

\footnotetext{
${ }^{6}$ For recent evidence on the upward bias in the distribution of recommendations see Barber et al. (2007), Lin et al. (2005) and Chen and Matsumoto (2006).

${ }^{7}$ A related provision of NASD 2711 is that every brokerage firm must disclose in each of its research reports its definitions for buy, hold, and sell. These definitions were not commonly disclosed prior to the implementation of NASD 2711 (see footnote 7, Barber et al, 2007b).
} 


\section{Research Design}

In this section we present the research design of the study. We construct a trading strategy that tries to exploit gender differences in analyst opinions on the individual asset level. ${ }^{8}$ The motivation for doing so is due to de Goeij and Smedts (2008) who show that gender differences in recommendations exist on the individual asset level. This implies that for a given asset, if male and female analysts act similarly within their gender group, the male consensus recommendation differs from the female consensus recommendation.

\subsection{Portfolio Construction Methodology}

For each asset $i$ for which we observe outstanding recommendations in a given month $t-1$, we calculate the gender specific consensus recommendation $\bar{A}_{i, t-1}^{g}$, which is defined as the average of all outstanding gender-specific recommendations by analyst $j$ for each firm $i$ on the last day of month $t-1$, denoted as $R E C_{i, j, t-1}$. Formally,

$$
\bar{A}_{i, t-1}^{g}=\frac{1}{n_{i, t-1}^{g}} \sum_{j=1}^{n_{i, t-1}^{g}} R E C_{i, j, t-1},
$$

where $n_{i, t-1}^{g}$ is the number of analysts who have outstanding recommendations for the firm on the last day of month $t-1$ and $g=$ male, female. We compute the Gender Consensus Difference $(G C D)$ between male and female analysts as:

$$
G C D_{i, t-1}=\bar{A}_{i, t-1}^{\text {male }}-\bar{A}_{i, t-1}^{\text {female }}
$$

The Gender Consensus Difference is negative (positive) when female (male) analysts are more optimistic about the stock than male (female) analysts. In each month, we rank all assets by their $G C D$-rating and we sort them into six equally-

\footnotetext{
${ }^{8}$ An investement strategy that exploits the level of recommendations cannot be implemented profitably. We find negative abnormal returns for gender-split portfolios based on the most favorably recommended stocks (results are availaible from the authors upon request). This is consistent with analysts being too optimistic. Interestingly, we observe a further decline in the performance of all female portfolios after August 2002. Simultaneously female participation in the industry drastically declines. This suggests that the "better performing" female analysts left their job, which is consistent with recent experimental evidence set forth by Niederle and Vesterlund (2007).
} 
sized portfolios. ${ }^{9}$ Portfolio 1 thus contains assets for which female analysts issue (on average) most favorable recommendations compared to their male colleagues. Alternatively, portfolio 6 contains assets for which male analysts issue (on average) most favorable recommendations compared to their female colleagues. This strategy thus implies that the level of the assets' (consensus) recommendation does not matter for portfolio selection, but only the relative (male versus female) consensus level. Portfolios can consist of firms with have a very favorable consensus recommendation, for example a "buy" recommendation and firms with a very unfavorable consensus recommendations, for example a "sell" recommendation.

In order to keep transactions costs limited, we use a monthly investment strategy. Once we have determined the composition of each portfolio $p$ on the last trading day of month $t-1$, we calculate the value-weighted return for date $t$. Such value weighted scheme allows us to better capture the economic significance of our results. The portfolio return $R_{p, t}$ is given by:

$$
R_{p, t}=\sum_{i=1}^{n_{p, t-1}} w_{i, t-1} R_{i, t}
$$

where $w_{i, t-1}$ is the market value of equity for firm $i$ divided by the aggregate market capitalization of all firms in portfolio $p$ determined at the close of trading on the last trading day of month $t-1 ; R_{i, t}$ is the return on the common stock of firm $i$ during month $t$ and $n_{p, t-1}$ is the number of firms in portfolio $p$ at the close of trading on the last trading day of month $t-1$.

\subsection{Performance Evaluation}

To determine the profitability of trading on the recommendations, we evaluate the returns that the strategy yields. We use different benchmarks to evaluate abnormal returns. Such analysis not only sheds light on the obtained returns, but also describes the underlying risks of the strategies. This procedure allows us to analyze whether systematic differences in risk preferences exist between male and female analysts.

\footnotetext{
${ }^{9}$ The number of portfolios to construct is in fact arbitrary. Six portfolios are chosen to achieve a high degree of seperation across firms while retaining sufficient power for our tests. Qualitative similar results are obtained when forming 4, 8, 10 or 12 equal size portfolios.
} 
We focus on different aspects of the portfolios' performances. We analyze the risk-adjusted outperformance, and study the risks inherent in the strategies. We use the Capital Asset Pricing Model, the three-factor Fama and French (1993) model and the four-factor model of Carhart (1997) as benchmark models. The four-factor model, which nests the CAPM and three-factor model, implies the estimation of the following monthly time-series regression:

$$
R_{p, t}-R_{f, t}=\alpha_{p}+\beta_{p}\left(R_{m, t}-R_{f, t}\right)+s_{p} S M B_{t}+h_{p} H M L_{t}+m_{p} M O M_{t}+\varepsilon_{p, t}
$$

where

$R_{p, t}=$ the month $t$ portfolio return,

$R_{f, t}=$ the month $t$ return on treasury bills having one month until maturity,

$R_{m, t}=$ the month $t$ market return,

$\varepsilon_{p, t}=$ the regression error term.

Furthermore, $S M B_{t}$ is the month $t$ return of the zero-cost portfolio, that consists of a value-weighted portfolio long in small stocks and short in large stocks, $H M L_{t}$ is the month $t$ return of the zero-cost portfolio, consisting of a value-weighted portfolio long in high book-to-market stocks and short in low book-to-market stocks and finally $M O M_{t}$ is a zero investment portfolio related to price momentum. The momentum factor is the equally weighted month $t$ average return of the firms with the highest 30 percent return over the 11 months through month $t-2$, less the equally weighted month $t$ average return of the firms with the lowest 30 percent return over the 11 months through month $t-2$.

A comparison of the estimated coefficients across the $G C D$-rated portfolios allows us to compare the relative outperformance of each strategy, as well as the risk profile of each strategy. First, the estimated $\alpha$ coefficients allow us to compare the risk-adjusted outperformance of the portfolios. Second, the estimated factor coefficients $(\beta, s, h$ and $m$ ) shed light on the risk profile of the gender-based investment strategies. A comparison across the portfolios allows us to detect any differences in risk profile, that might explain any performance differences. 


\subsection{Transaction Costs}

The portfolio returns are calculated without trading costs arising from the bid-ask spread, brokerage commissions, and the market impact of trading. Therefore, we asses the size of the transaction costs by calculating the turnover of each portfolio. We use the strategy of Barber et al. (2001). The turnover of a portfolio $p$ during trading month $t$ is defined as the percentage of the portfolio holdings (as of the close of trading on the last day of month $t-1$ ) that has been sold off on the last day of month $t$.

Turnover is calculated following a three-step procedure. First, for each stock $i$ in portfolio $p$ as of the close of trading on the last trading day of month $t-1$, we calculate the fraction $G_{i, t}$ it comprises of the portfolio at the end of trading on the last day of month $t$ if there were no portfolio rebalancing. This fraction is defined as:

$$
G_{i, t}=\frac{w_{i, t-1}\left(1+R_{i, t}\right)}{\sum_{i=1}^{n_{p, t-1}} w_{i, t-1}\left(1+R_{i, t}\right)} .
$$

Next, $G_{i, t}$ is compared to the fraction firm $i$ makes up of portfolio $p$ at the end of trading on the last trading day of month $t, F_{i, t}$. The difference between the fraction $G_{i, t}$ and the fraction $F_{i, t}$ captures all portfolio rebalancing as a result of changes in analyst recommendations and changes in relative market capitalizations. Finally, we sum the existing decrease in percentage holdings of each of the stock that are part of portfolio $p$ in month $t$ which yields the monthly portfolio turnover. ${ }^{10}$ Turnover during month $t$, denoted by $T O_{p, t}$, is therefore calculated as

$$
T O_{p, t}=\sum_{i=1}^{n_{p, t}} \max \left(G_{i, t}-F_{i, t}, 0\right) .
$$

Annual turnover is calculated by multiplying $T O_{p, t}$ by 12 .

\footnotetext{
${ }^{10}$ Alternatively, we could take into account both the decrease as well as the increase in percentage holdings for each portfolio and consider the one-way transaction costs, instead of round-trip transaction costs.
} 


\section{Portfolio Characteristics and Returns}

Table 3 provides descriptive statistics for portfolios formed on the basis of the $G C D$ rating for each asset. On average each portfolio contains 225 assets per month. Column (2) shows that the stock selection procedure results in a split between portfolios 1-3, which represent firms for which female analysts issue, on average, more favorable recommendations than male analysts and portfolios 4-6 which consist of firms for which male analysts issue more favorable recommendations. Columns (3) and (4) document the gross returns and the market-adjusted returns of all portfolios, respectively. All gross returns are significantly different from zero. We observe that the extreme $G C D$-rated portfolio 1 yields the lowest returns, while the more moderate $G C D$-rated portfolio 3 yields the highest returns. Interestingly, once corrected for market risk (measured as a value-weighted NYSE/AMEX/Nasdaq index), none of the portfolio returns remain significant. Relative to the performance of a market portfolio, there does not seem to be any outperformance of the $G C D$-rated portfolios. To measure how the $G C D$-rated portfolios perform, relative to a benchmark that accounts for market risk, size, book-to-market and price momentum characteristics, columns (1) - (3) of Table 4 present the estimated intercepts from the CAPM, the Fama-French model and the Four Factor model, respectively. Table 4 shows that the portfolios consisting of assets for which female analysts issue more favorable recommendations, perform better than the portfolios consisting of the more favorable male analyst advice. Portfolio 3, which consists of assets with a small but negative $G C D$-rating, shows a significant outperformance of about 32 basis points a month, relative to the Fama-French model and the Four-Factor model. For all other portfolios however, the outperformance is not statistically different from zero.

Table 4 also presents the incurred transaction costs from following the $G C D$ strategies. In column (4) we present the annual turnover for each of the portfolios. Annual turnover lies between $40.3 \%$ and $54.1 \%$. There does not seem to be any particular pattern across the $G C D$-rated portfolios. Note that due to our monthly portfolio strategy, average turnover is considerably lower than the daily investment strategy suggested by Barber et al. (2001). In addition, the portfolios in our sample contain, on average, fewer assets, which also reduces turnover. Following Barber et al. (2001) we choose the round-trip transaction costs for our portfolios at 1.31 
percent of share value traded. ${ }^{11}$ The columns (5) - (7) present abnormal returns net of transactions costs. Portfolio 3 yields net abnormal returns of almost 3.2 percent annually relative to the Fama-French and Four Factor model. This makes the investment strategy very profitable indeed. This finding suggests that it is possible for investors to profitably exploit gender heterogeneity among financial analysts. Investors should buy a portfolio of assets with a small, but positive $G C D$-rating, thus choosing assets for which female analysts are a little bit more optimistic than male analysts.

Table 5 presents the estimated factor loadings of the $G C D$-sorted portfolios, as measured by the four-factor model. The risk loadings do seem to differ across the $G C D$-sorted portfolios. The $S M B$ factor has a significant negative loading for the Portfolios 1 - 3, indicating that female analysts on average recommend large-cap firms. On the other hand, portfolios 5 and 6, which consists of assets for which male analysts issue more favorable recommendations, do have significant negative loadings for the momentum factor $M O M$, which implies they favour assets that have underperformed in the last 12 months. In addition, the loadings for the $H M L$ factor are significantly negative for portfolios 2 and 3 (female preferred), while they are significantly positive for portfolios 5 and 6 (male preferred). Portfolio 3 , with the small but negative $G C D$-rating seems to have a distinct risk-return profile. This portfolio is characterized by large cap firms with a low book-to-market value and below average market risk. Overall, these results show that constructing portfolios on the basis of asset specific gender recommendation heterogeneity, yields portfolios with different risk-return characteristics.

While this analysis indicates that a profitable gender-based strategy can be pursued, the next section investigates whether these findings are robust to different stock selection criteria, regulatory changes and the inclusion of a market-wide liquidity factor. Moreover, this enables us to better understand the potential drivers of these findings.

\footnotetext{
${ }^{11}$ For our sample 1996 - 2006, these round-trip transaction costs are probably higher than investors have to pay, as several studies have shown that transaction cost have decreased significantly in our sample (see for example, Hasbrouck (2006)). By taking this upper bound for transaction costs, we are conservative about the net returns that can be realized using the investment strategy.
} 


\section{Robustness}

In this section we investigate whether the findings of the previous section are robust. First, we investigate whether the result of the previous section is robust for different stock selection criteria. Second, due to regulatory changes in September 2002, we observe that the distribution of issued recommendations has changed. We investigate whether this change affects the performance of the trading strategy. Finally, we analyze whether the exposure to a market-wide liquidity factor can explain the observed pattern in abnormal returns.

\subsection{Different Stock Selection Criteria}

In this section we investigate whether stock selection criteria influences the results above. We investigate three different stock selection strategies. First, we use fixed cutoff points to define the portfolio compositions. Second, we presort on industries, to correct for a potential industry-bias. Third, a presorting on firm-size is undertaken.

\subsubsection{Fixed Cutoff Points}

As an alternative to dividing all assets equally among six portfolios, we follow Barber et al. (2001) and define fixed cutoff points to determine the portfolio composition during each month $t$. Portfolio 1 consists of stocks that have a GCDrating equal or smaller than -1 , portfolio 2 consists of assets with a $G C D$-rating between -1 and -0.5 , while the remaining four portfolios have cutoff points in the ranges of $(-0.5 ; 0],(0 ; 0.5],(0.5 ; 1]$ and larger than 1 , respectively. By construction, portfolios 1 - 3 contain the assets for which more favorable female recommendation are issued, while portfolios $4-6$ contain assets for which more favorable male recommendation are issued.

Table 6 provides the return characteristics of all portfolios. Columns (1) and (2) document the gross returns and the market-adjusted returns of all portfolios. A pattern that is similar to the results of the previous section can be observed. We observe that the extreme portfolios 1 and 6 yield the lowest returns, while the moderate portfolios yield the highest returns. Portfolio 3 yields a statistically significant gross return of 93 points a month. Similar to the previous section, the average market-adjusted portfolio returns are not significant. Column (3) presents 
the abnormal gross returns per month relative to the Four Factor model. ${ }^{12}$ Consistent with the results of the previous section, only portfolio 3 shows a significant outperformance consisting of between 23 basis points a month. This is slightly lower than the findings of the previous section, but still highly significant at the $5 \%$ level. Annual turnover percentages are between 42 and 63 percent as shown in column (4) which is line with previous findings. These estimates imply a net abnormal return 2.5 percent annually for portfolio 3 .

The risk profiles of the portfolios constructed using fixed cutoff points are shown in Table 7. The estimates for the factors loadings of the four factor model, presented in columns (1) - (4) are in line with the estimates for the equal size portfolios presented in Table 5. Portfolio 1, shows no significant factor loadings, while portfolio 6 reflects the risks of value stocks that have performed poorly in the past. Again, portfolio 3 consists of large growth firms with below average market risk.

\subsubsection{Industry-Sorting}

The interested reader might argue that the asset specific gender differences in analyst recommendations are industry specific. If this is indeed the case, this leads to an over- or under representation of industry specific assets in a particular portfolio. We therefore follow an approach similar to Rouwenhorst (1999). Instead of dividing all $G C D$-rated assets equally between six portfolios, we first divide all assets equally among six portfolios for each industry separately and in a second step we combine all industry specific $G C D$-rated portfolios into six $G C D$-rated portfolios overall. The results for these industry-corrected portfolios are similar as for the equal size portfolios. Table 8 reports the return-characteristics of the portfolios while the estimated Four Factor risk loadings are shown in Table 9. Portfolio 3 yields a statistically significant gross return of 98 basis points and a significant outperformance of 26 basis points relative to the Four Factor model. The net annual return amounts to 2.6 percent annually. In addition, in terms of risk exposures the results are very much in line with previous findings. Portfolio 3 consists of large growth firms with below average market risk, while portfolio 6 reflects value firms that have performed poorly in the past. Overall, The investment strategy that exploits the individual assets' consensus difference rating

\footnotetext{
${ }^{12}$ The results of the nested models, i.e. the CAPM and the Fama-French model are available on request from the authors.
} 
yields portfolios that show different characteristics across $G C D$-rated portfolios which are consistent and robust to industry specific corrections.

\subsubsection{Firm Size-Sorting}

In this section we investigate whether the investment strategy generates significant abnormal net returns for subsets of small, medium and large firms. There are several reasons to perform this robustness analysis. First, there is typically less information publicly available about smaller firms and as a result the impact of the analysts recommendations could be larger. Furthermore, as Barber et al. (2001) note, it is likely that the investors' ability to arbitrage away any excess returns will be lowest for these small firms. However, the profitability of the $G C D$-rated portfolio strategy does not depend on taking a contrarian position in either portfolio and we therefore argue that this explanation is not so important. Finally, the estimated factor loadings of the Four Factor model indicate that portfolio 3 consists of large-cap firms. As large firms represent a greater share of the investment opportunities available in the market, it would make such investment strategy easier and cheaper to implement.

Table 10 presents the returns for the size partitions, assuming monthly rebalancing. First, we sort all assets by firm size and split the sample equally in three subsamples. Next for every subsample, we sort all assets by $G C D$-rating and divide them equally among six portfolios. This approach results in 18 double sorted size- $G C D$ portfolios. ${ }^{13}$ In the columns (2) - (4) the mean returns are presented. The smallest firms yield the largest gross mean returns, where $G C D$-rated portfolio 5 has the largest average return of almost 1.5 percent per month and $G C D$-rated portfolio 4 has the smallest average return of almost 94 basis points per month. On the other hand, in the subsample of large firms, $G C D$-rated portfolio 3 shows the highest gross average returns of about 1 percent per month.

All mean-adjusted gross returns are insignificantly different from zero, but the most interesting part of the table are columns (8) - (10) where the gross monthly

\footnotetext{
${ }^{13}$ In addition we investigated whether the results are robust to different levels of recommendation dispersion. Diether et. al (2002) show that stocks with higher dispersion in analysts' earnings forecasts earn lower future returns. In a similar vein, we investigate whether such dispersion effect is present in analysts' recommendations. We find that the main result of the paper can only be observed in the subsample of medium dispersion stocks. These results are available from the authors upon request.
} 
abnormal returns, relative to the Four Factor model, are presented. Only GCDrated portfolio 3 in the large firm subsample yields significant positive abnormal returns of 32 basis points per month. In contrast, $G C D$-rated portfolio 3 in the small and medium size subsample have negative abnormal returns, although not significantly different from zero. This implies that the outperformance of the assets for which female analysts are on average a little bit more optimistic compared to male analysts is driven by large cap firms.

Annual turnover, presented in columns (11) - (13), is almost twice as large for the large firms compared to the small firms, while the smallest turnover is observed for all medium firm size portfolios. This implies that especially for the subsample of large firms, the $G C D$-rating changes more often, causing more portfolio changes and therefore higher turnover. Across $G C D$-rated portfolios no particular pattern is observed, in line with previous findings. As mentioned above, larger firms have the advantage that transactions costs are lower. Using round-trip cost of 0.727 percent for large firms, we estimate net annual returns close to 3.5 percent for the larger firms in GCD-rated portfolio 3. This result implies that the investment strategy is straightforward to implement as it is driven by investing in larger size firms.

\subsection{The Impact of Regulatory Changes}

Several studies have shown that analysts have been overoptimistic in recommending stocks. After the collapse of technology stocks, this upward bias in analyst recommendations became known publicly and caused increased scrutiny of analysts' practices by the Securities and Exchange Commission. In addition, in the wake of numerous high-profile corporate scandals the National Association of Securities Dealers (NASD) proposed rule 2711, which was approved by the SEC on May 8, 2002 and enforced on September 9, 2002. The rule contains a disclosure provision which entails that every brokerage firm is required to disclose in its research reports the distribution of stock ratings across its coverage universe. This has lead to a change in the recommendation distribution of security analysts. In this section we investigate the effects of the regulatory changes on the $G C D$-rated portfolio strategy.

Table 11 show the performance relative to the Four Factor model of the equal 
size portfolio investment strategy before September 2002 and after August 2002, when the regulatory changes came into effect. Column (2) shows the abnormal gross returns, relative to the Four Factor model, when taking into account all observations before September 2002. Only portfolio 3 shows significant ${ }^{14}$ abnormal returns of 33 basis points a month. Taking into account annual turnover, presented in column (3), this yields net abnormal returns of 3.3 percent annually. After the regulatory changes in September 2002, the investment strategy remains profitable relative to the Four Factor model. Portfolio 3 yields net abnormal returns of 2.8 percent annually. Note that the estimate after August 2002 has a higher t-value even when the second half of the sample covers only 52 months. In addition, after August 2002, portfolio 5 yields significant net abnormal annual returns of 2.9 percent a year (when shorting the portfolio). This finding is almost a complete reverse of the performance of portfolio 5 before August 2002. This finding is however not robust when considering other stock selection criteria. Overall, we conclude that the profitability of the investment strategy that consists of purchasing the assets in $G C D$-rated portfolio 3 is robust for the regulatory changes of September 2002.

\subsection{Gender Difference Consensus Portfolios and Market- Wide Liquidity Exposure}

As a final robustness check, we investigate whether exposure to market-wide liquidity can potentially explain the abnormal returns of the $D C$-rated portfolio 3 . The motivation is due to Pastor and Stambaugh (2003) who show that systematic liquidity risk is a priced risk factor and especially Sadka (2006) who shows that a liquidity factor is priced within the context of momentum and post-earningsannouncement drift portfolio returns.

From the WRDS system we downloaded 4 market-wide liquidity series. These are the liquidity level, $L I Q(P S)_{t}^{L}$, and liquidity innovation, $L I Q(P S)_{t}^{I}$, from Pastor and Stambaugh (2003) and the transatory-fixed liquidity factor, $L I Q(S)_{t}^{T F}$, and the permanent-variable liquidity factor, $\operatorname{LIQ}(S)_{t}^{P V}$, from Sadka (2006). The Pastor and Stambaugh (2003) liquidity measures cover our entire sample period, while the Sadka (2006) liquidity series run through December 2005. When investigating the impact of the Sadka (2006) measures, we therefore use a sample from

\footnotetext{
${ }^{14}$ At the 10 percent significance level.
} 
January 1996 - December 2005.

In contrast to the factors used in (4), the market-wide liquidity factors do not represent the returns on a zero-cost portfolio. Therefore, if we add a liquidity factor to the Four Factor model as a 5th factor, the intercept can no longer be interpreted as Jensen's alpha to measure the outperformance of our portfolios. Therefore, we follow an alternative approach. For every portfolio we estimate equation (4) and calculate the Four Factor portfolio residuals $e_{p t}$. Next, we estimate the following time-series equations simultaneously using OLS:

$$
e_{p t}=\gamma_{0 p}+\gamma_{1 p} L I Q_{t}+\eta_{p t}
$$

where $L I Q_{t}$ represents one of the four liquidity measures described above, $\gamma_{0 p}$ and $\gamma_{1 p}$ are parameters that have to be estimated and $\eta_{p t}$ is an error term, for all portfolios $p$. In order to obtain variability in the cross-sectional dimension, we perform the regressions for the double sorted size portfolios of subsection 5.1.3. Table 12 shows the $\gamma_{1}$ estimates across the 18 double sorted size- $G C D$ portfolios.

When interpreting the estimation results, we are especially interested in differences of the $\gamma_{1}$ estimates across the portfolios and the sign of the estimates. In Table 12 only a few individual estimates are significant. In addition, the Wald test for simultaneous equality of all $\gamma_{1}$ estimates can only be rejected for the transatoryfixed liquidity factor (see Sadka (2006)). However, a particular pattern across the liquidity exposures cannot be observed. Ultimately we are interested in any relationship between the abnormal return of the portfolios and liquidity exposure. In Figure 1 the estimated Jensen's alphas of Table 10 are plotted against the liquidity exposure estimates $\gamma_{1}$ of Table 12. In Figure 2 the estimated Jensen's alphas are sorted by size while the corresponding liquidity exposures are plotted as well. In all the subplots we cannot identify any relation between the abnormal returns and liquidity exposure. Indeed, cross-section regressions of Jensen's alphas on the estimated liquidity exposures $\widehat{\gamma_{1}}$ 's (and a constant term), do not yield any significant estimates for any of the liquidity measures, including the transatory-fixed liquidity factor. This shows that there is no relationship between market-wide liquidity exposure and double sorted size-GCD portfolios.

We summarize our findings as follows. Exploiting gender heterogeneity for individual assets results in the (significant) outperformance of a portfolio that consists 
of assets for which female analysts issue slightly more favorable recommendations compared to male analysts. The firms in the portfolio can be characterized as large growth firms with below average market risk and the outperformance is not related to market-wide liquidity risk exposure.

\section{Concluding Remarks}

The goal of this paper is to investigate whether abnormal returns can be realized on investment strategies designed to exploit gender heterogeneity of analysts' stock recommendations. For each asset we calculate the Gender Consensus Difference $(G C D)$ defined as the male consensus recommendation minus the female consensus recommendation. Therefore, a negative $G C D$-rating implies that female analysts issue on average more favorable recommendations than male analysts. We document that in the 1996 - 2006 period, a strategy that consists of the monthly rebalancing of a portfolio that consists of buying stocks with a small, but negative $G C D$-rating, yields net annual abnormal returns of 3.2 percent after controlling for market risk, size, book-to-market and price momentum effects.

This finding is robust to different stock selection techniques. Correcting for potential biases in the portfolio selection procedure still results in a significant outperformance of the portfolio that consists of assets with the smallest negative $G C D$-rating. This strategy yields abnormal returns of minimally 2.5 percent annually. We document that the outperformance is only present in the subsample of large firms. The result is robust to regulatory changes in September 2002. Before September 2002, the strategy yields net annual abnormal returns of 3.3 percent, while after August 2002, outperformance decreases to 2.8 percent annually. We show that the outperforming portfolio consists of assets of large growth firms with below average market risk. Finally we show that the outperformance is not related with market-wide liquidity risk exposure.

This study shows that on the individual asset level, gender heterogeneity in the recommendation issuing process of financial analysts can be exploited by investors. Whether this result can be explained by differences in personal analyst characteristics, such as age, experience or working environment is left for future research. 


\section{References}

[1] Barber, B., R. Lehavy, M. McNichols and B. Trueman, 2001. Can Investors Profit from the Prophets? Security Analyst Recommendations and Stock Returns. Journal of Finance 56: 531-563.

[2] Barber, B.M., R. Lehavy and B. Trueman, 2007. Comparing the Stock Recommendation Performance of Investment Banks and Independent Research Firms. Forthcoming in Journal of Financial Economics.

[3] Barber, B.M., R. Lehavy, M. McNichols and B. Trueman, 2007b. Buys, Holds, and Sells: The Distribution of Investment Banks' Stock Ratings and the Implications for the Profitability of Analysts' Recommendations. Forthcoming in Journal of Accounting Research.

[4] Barber, B.M. and T. Odean, 2001. Boys Will Be Boys: Gender, Overconfidence and Common Stock Investments. Quarterly Journal of Economics 1: 261-292.

[5] Bidwell, C., 1977. How Good is Institutional Brokerage Research? Journal of Portfolio Management 77: 26-31.

[6] Cadsby, C.B. and E. Maynes, 2005. Gender, Risk Aversion and the Drawing Power of Equilibrium in an Experimental Corporate Takeover Game. Journal of Economic Behavior and Organization 56: 39-59.

[7] Carhart, M. M., 1997. On Persistence in Mutual Fund Performance, Journal of Finance 52: 57-82.

[8] Chen, S. and D.A. Matsumoto, 2006. Favorable versus Unfavorable Recommendations: The Impact on Analyst Access to Management-Provided Information. Journal of Accounting Research 44: 657-689.

[9] Clement, M.B. and S.Y. Tse, 2005. Financial Analyst Characteristics and Herding Behavior in Forecasting. Journal of Finance 60: 307-341.

[10] Conrad, J., B. Cornell, W. Landsman and B. Rountree, 2006. How do Analyst Recommendations Respond to Major News? Journal of Financial and Quantitative Analysis 41: 25-49. 
[11] Cowles, A., 1933. Can Stock Market Forecasters Forecast? Econometrica 1: 309-324.

[12] Croson, R. and U. Gneezy, 2004. Gender Differences in Preferences. Working Paper, Wharton School.

[13] De Goeij, P. and K. Smedts, 2008. Gender Differences Among Analyst Recommendations, Working paper, Tilburg University.

[14] Diether, K.B., C.J. Malloy, A. Scherbina, 2002. Differences of Opinion and the Cross Section of Stock Returns. Journal of Finance 57, 2113 - 2141.

[15] Diefenbach, R.E., 1972. How Good is Institutional Brokerage Research? Financial Analysts Journal 28: 54-60.

[16] Fama, E. and K.R. French, 1993. Common Risk Factors in the Returns of Stocks and Bonds. Journal of Financial Economics 33: 3-53.

[17] Hasbrouck, J., 2006. Trading Costs and Returns for US Equities: Estimating Effective Cost from Daily Data, Working Paper, New York University.

[18] Hong, H., J. Kubik and A. Solomon, 2000. Security Analysts' Career Concerns and Herding of Earnings Forecasts. Rand Journal of Economics 31: 121-144.

[19] Jegadeesh, N., J. Kim, S.D. Krische and C.M.C. Lee, 2004. Analyzing the Analysts: When Do Recommendations Add Value? Journal of Finance 59: 1083-1124.

[20] Jegadeesh, N. and J. Kim, 2007. Do Analysts Herd? An Analysis of Recommendations and Market Reactions. Available at SSRN: http://ssrn.com/abstract $=957192$

[21] Jianakoplos, N.A. and A. Bernasek, 1998. Are Women More Risk Averse? Economic Inquiry 36: 620-630.

[22] Lin, H., M. McNichols and P.C. O'Brien, 2005. Analyst Impartiality and Investment Banking Relationships. Journal of Accounting Research 43: 623-650.

[23] Ljungqvist, A., C.J. Malloy and F.C. Marston, 2007. Rewriting History. Available at SSRN: http://ssrn.com/abstract $=889322$ 
[24] National Investor Relations Institute, 2003. Analyst and IR Associations Form Joint Task Force on Corporate Issuer-Analyst Relations. News Release, May 12.

[25] Niederle, M. and L.Vesterlund, 2007. Do Women Shy Away from Competition? Do Men Compete too Much? Quarterly Journal of Economics 122: 1067 - 1101.

[26] Niessen, A. and S. Ruenzi, 2007. Sex Matters: Gender Differences in a Professional Setting. Available at SSRN: http://ssrn.com/abstract=966243

[27] Pastor, L. and R.F. Stambaugh, 2003. Liquidity Risk and Expected Stock Returns, Journal of Political Economy 111, 1135 - 1151.

[28] Rouwenhorst, K.G., 1998. International Momentum Strategies. Journal of Finance 53: 267-284.

[29] Sadka, R., 2006. Momentum and Post-Earnings-Announcment Drift Anomalies: The Role of Liquidity Risk. Journal of Financial Economics 80, 309 349.

[30] Stickel, S.E., 1995. The Anatomy of the Performance of Buy and Sell Recommendations. Financial Analysts Journal 51: 25 - 39.

[31] Sunden, A. and B.J. Surette, 1998. Gender Differences in the Allocation of Assets in Retirement Savings Plans. American Economic Review 88: 207-211.

[32] Thomson Financial, 1997-2007. Nelson's Directory of Investment Research 2232. Nelson, New York, N.Y.

[33] Welch, I., 2000. Herding Among Security Analysts. Journal of Financial Economics 58: 369-396.

[34] Womack, K.L., 1996. Do Brokerage Analysts' Recommendations Have Investment Value? Journal of Finance 51: 137 


\section{Tables}

Table 1: Descriptive Statistics of the Recommendations Sample

The recommendation data is obtained from $\mathrm{I} / \mathrm{B} / \mathrm{E} / \mathrm{S}$, while gender is identified using Nelson's Directory of Investment Research.

\begin{tabular}{c|rcccc}
\hline & No. Rec. & No. Firms Covered & No. Brokers & No. Analysts & \% Female \\
\hline 1996 & 13,130 & 2,126 & 172 & 1,933 & 16 \\
1997 & 15,018 & 2,490 & 201 & 2,392 & 16 \\
1998 & 18,714 & 2,743 & 213 & 2,818 & 17 \\
1999 & 19,685 & 2,783 & 215 & 3,023 & 17 \\
2000 & 18,728 & 2,705 & 206 & 2,974 & 17 \\
2001 & 20,193 & 2,532 & 193 & 2,954 & 16 \\
2002 & 31,189 & 2,595 & 198 & 3,039 & 15 \\
2003 & 23,877 & 2,490 & 257 & 2,943 & 14 \\
2004 & 20,885 & 2,540 & 285 & 2,974 & 13 \\
2005 & 17,107 & 2,491 & 273 & 2,596 & 13 \\
2006 & 15,645 & 2,407 & 240 & 2,237 & 13 \\
\hline all years & 214,171 & 4,716 & 528 & 6,852 & 17 \\
\hline
\end{tabular}




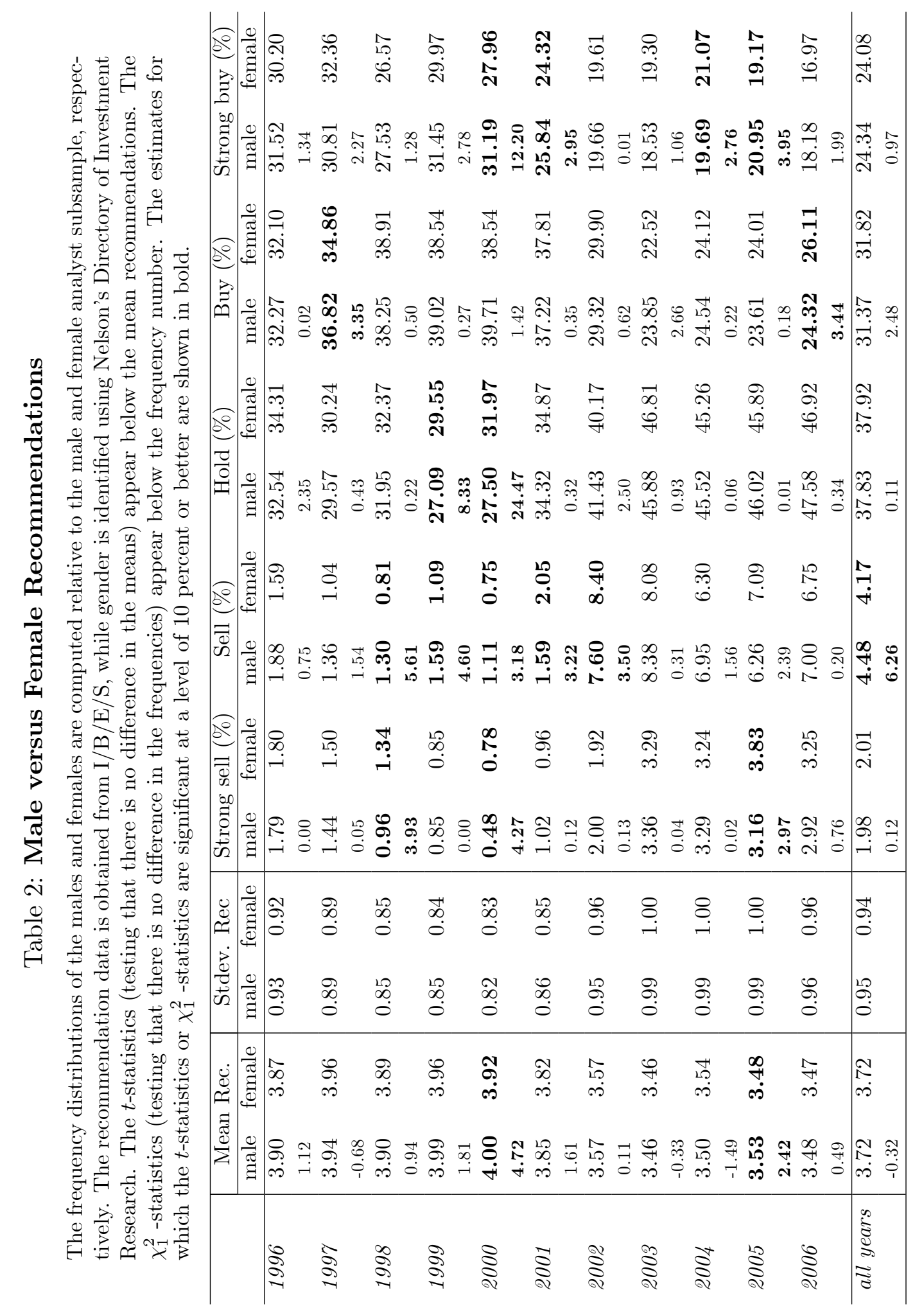




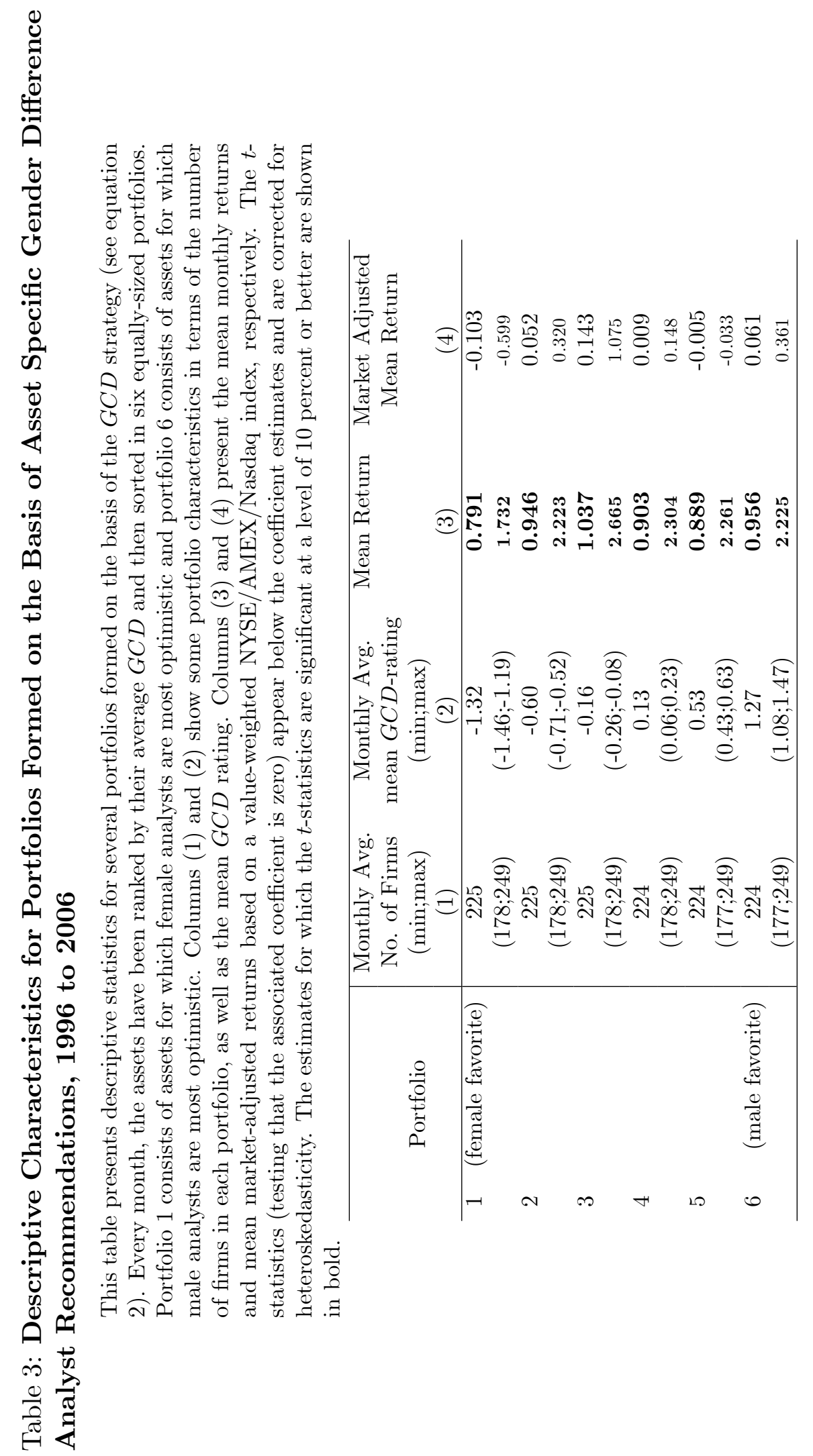




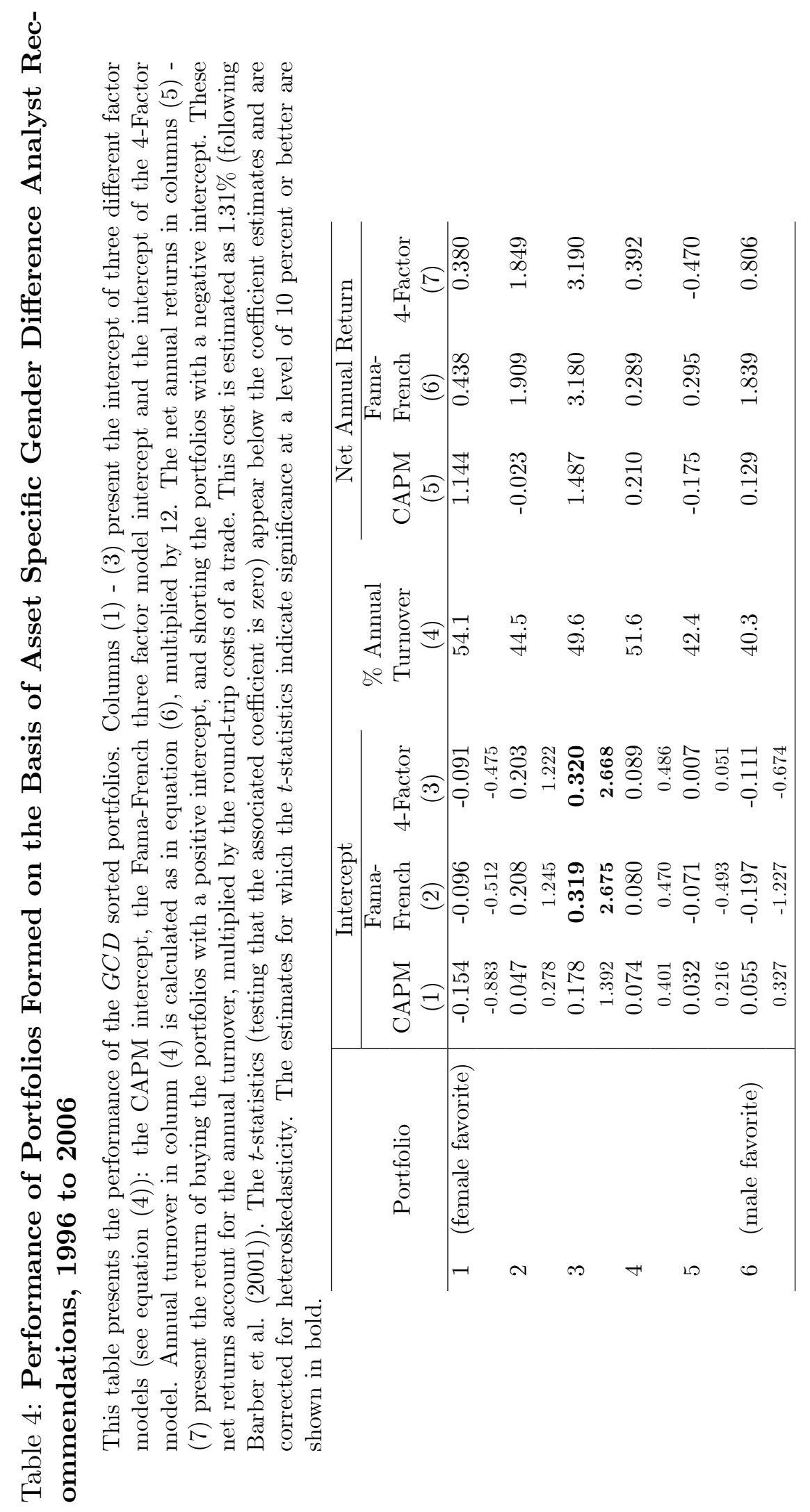




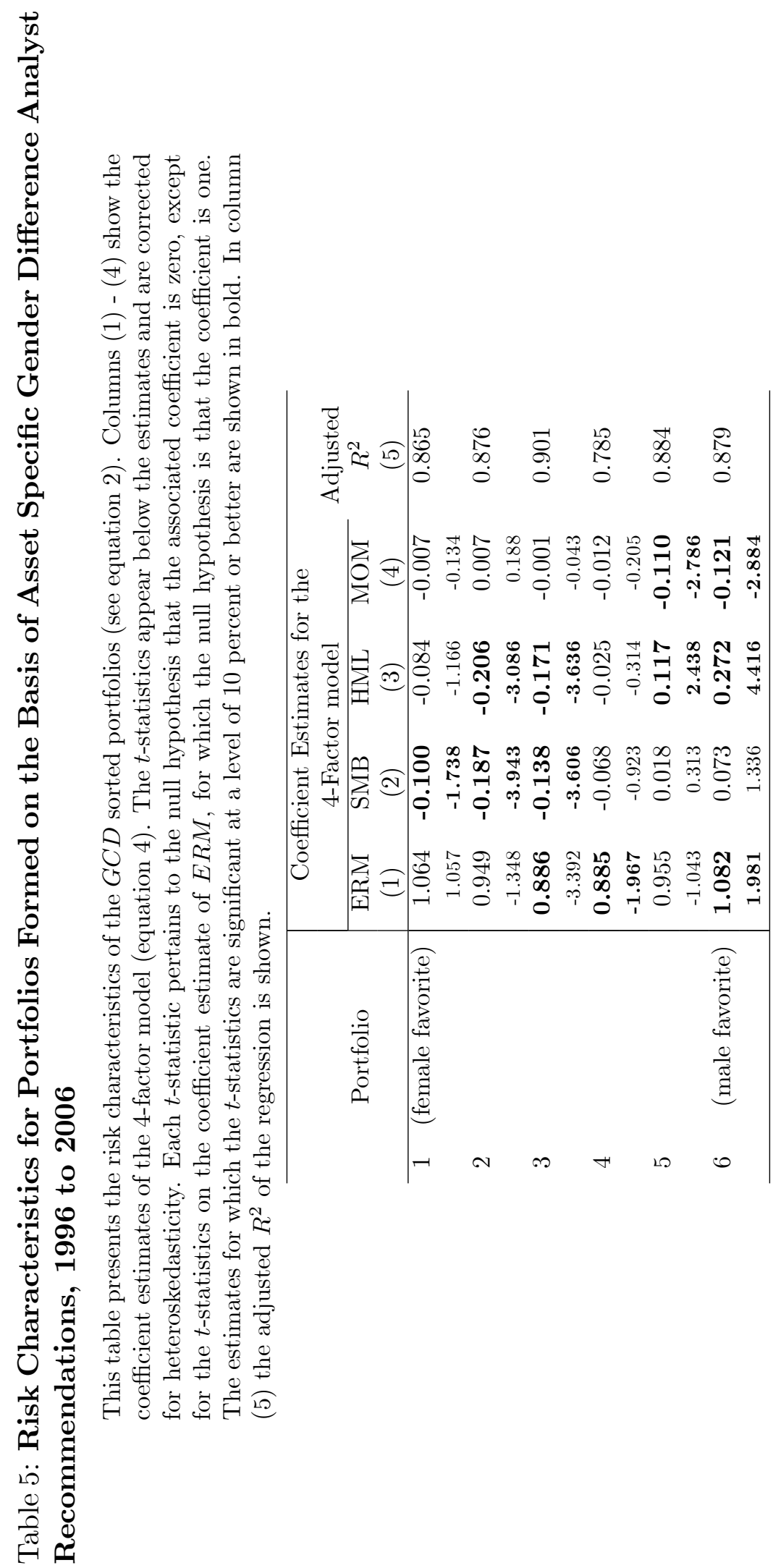




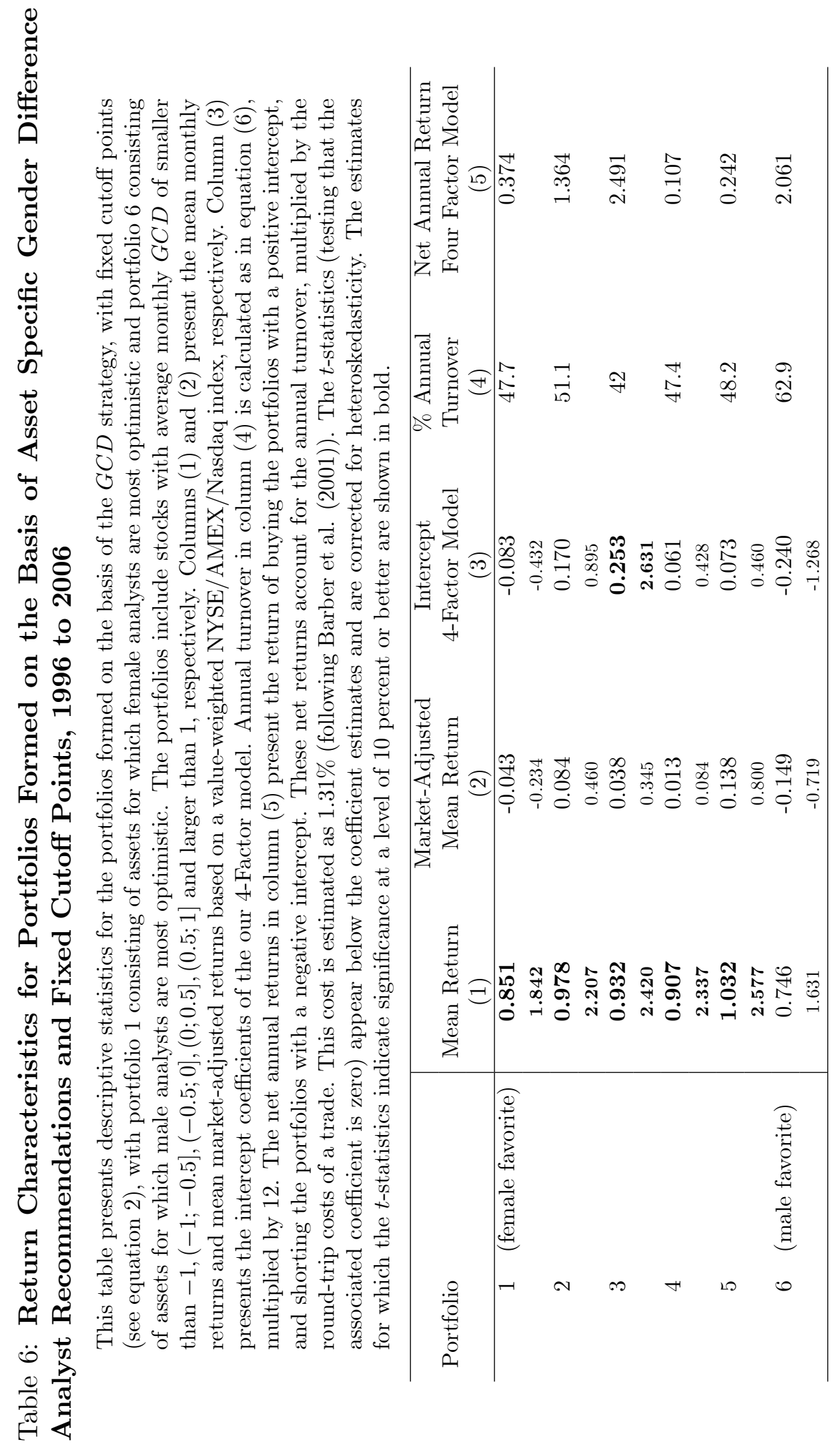




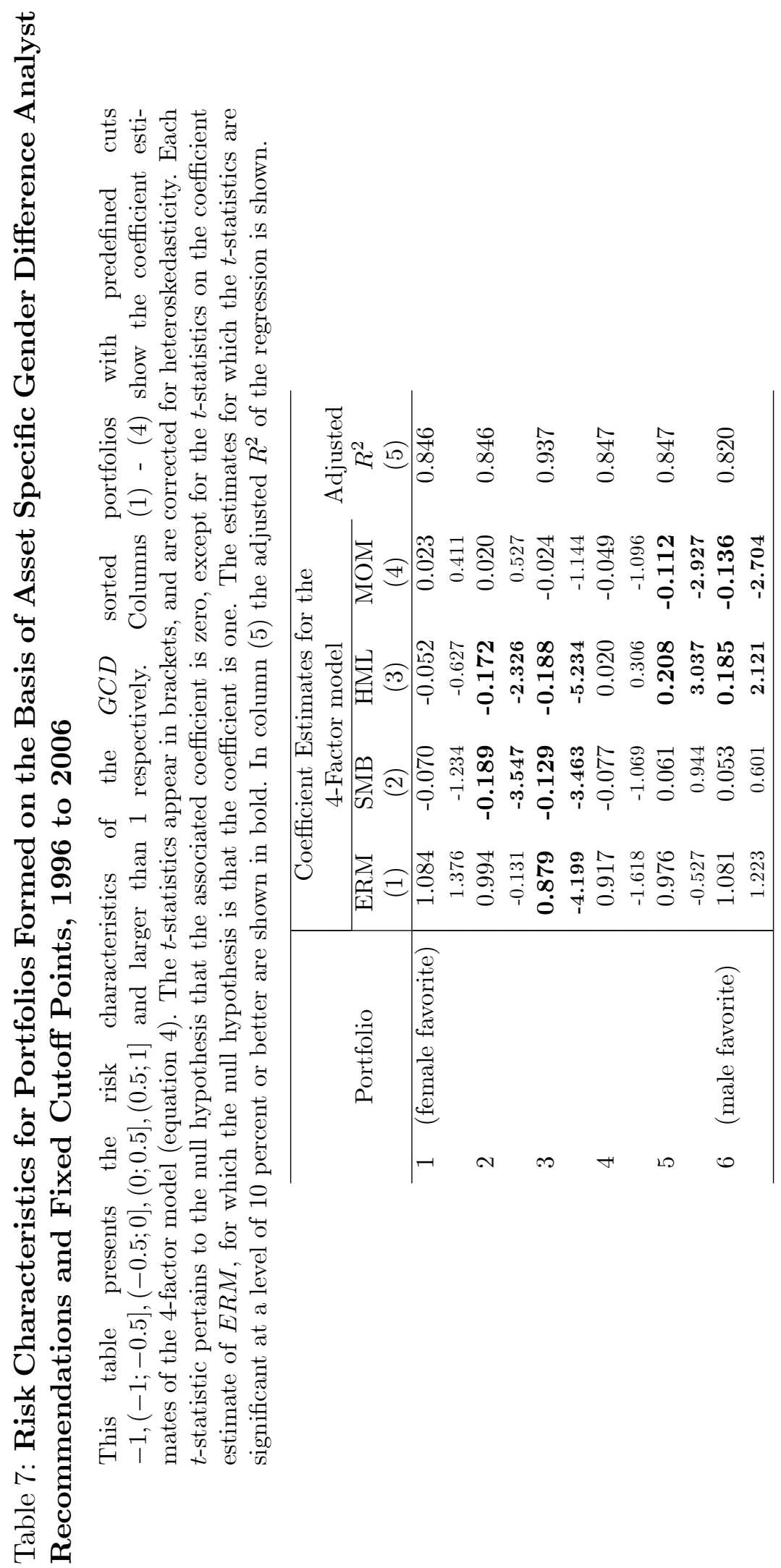




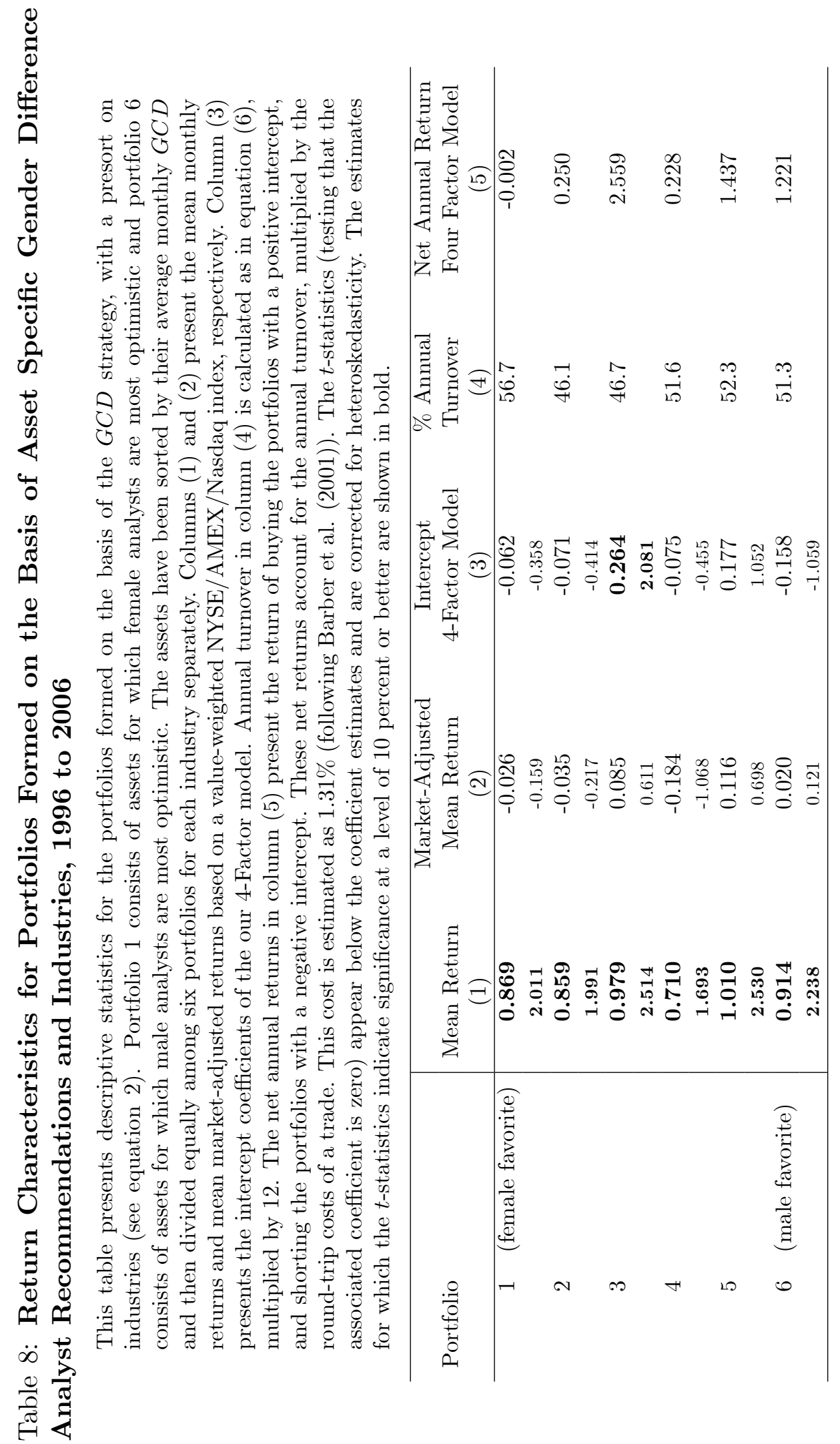




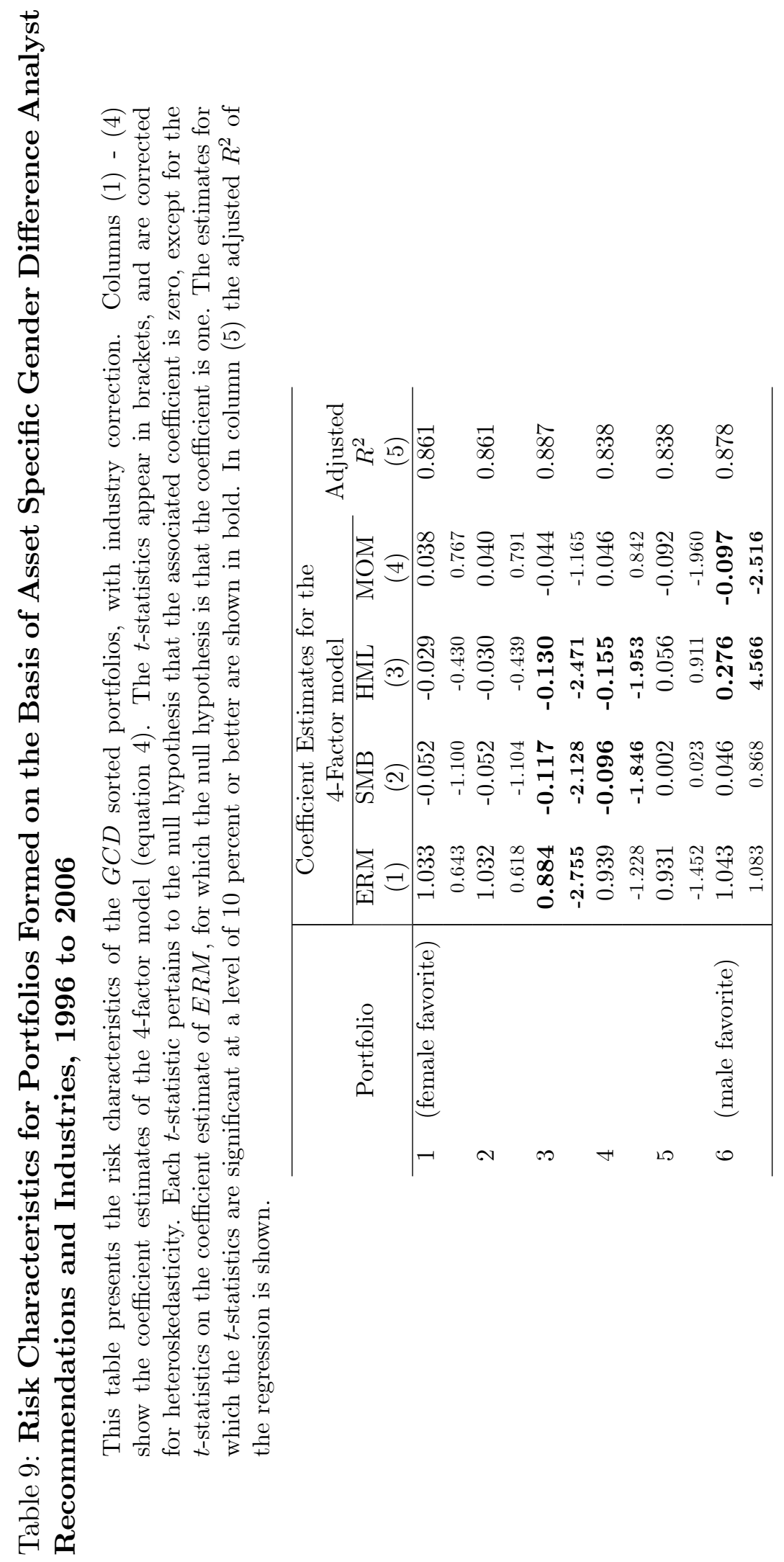




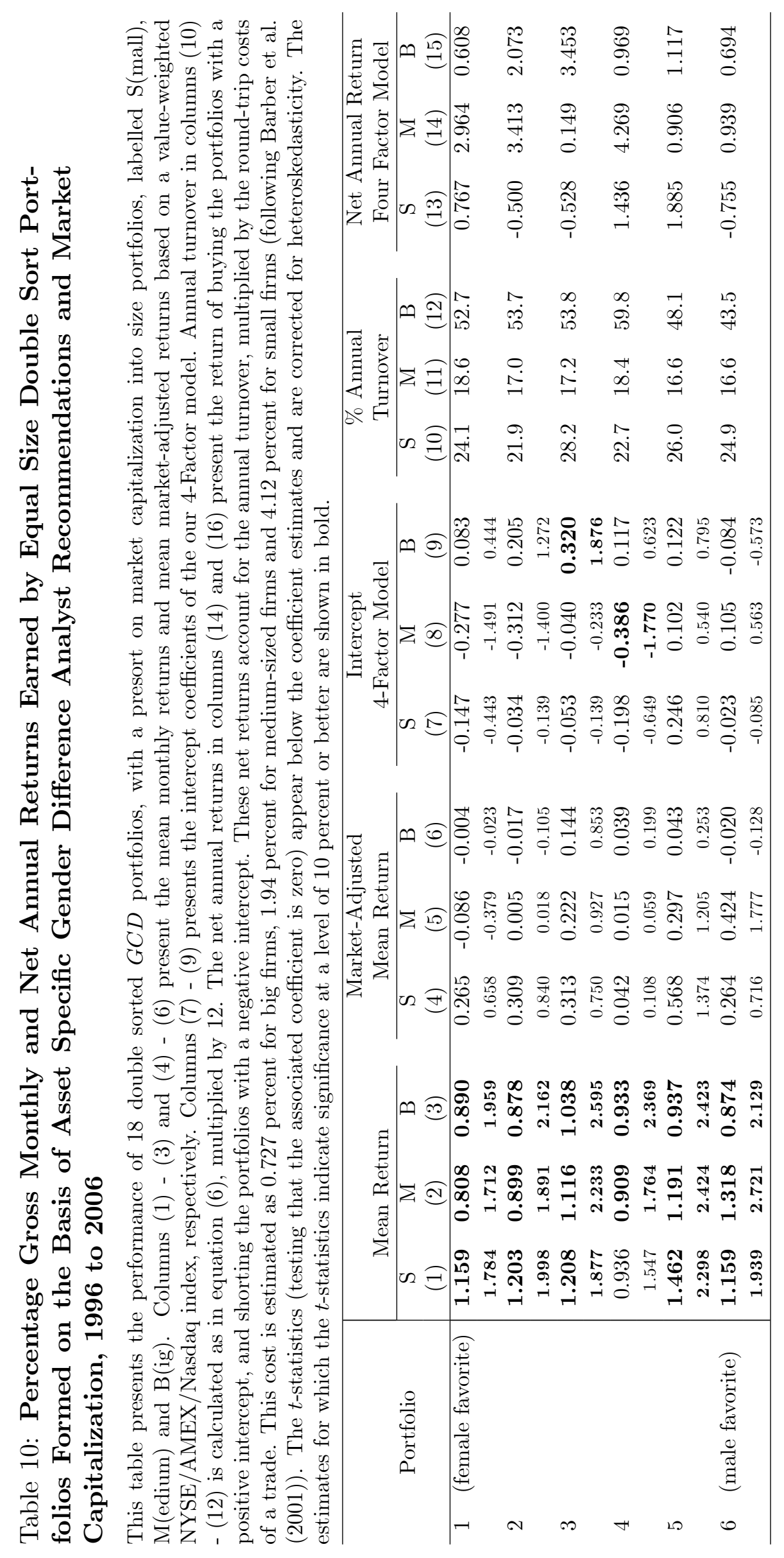




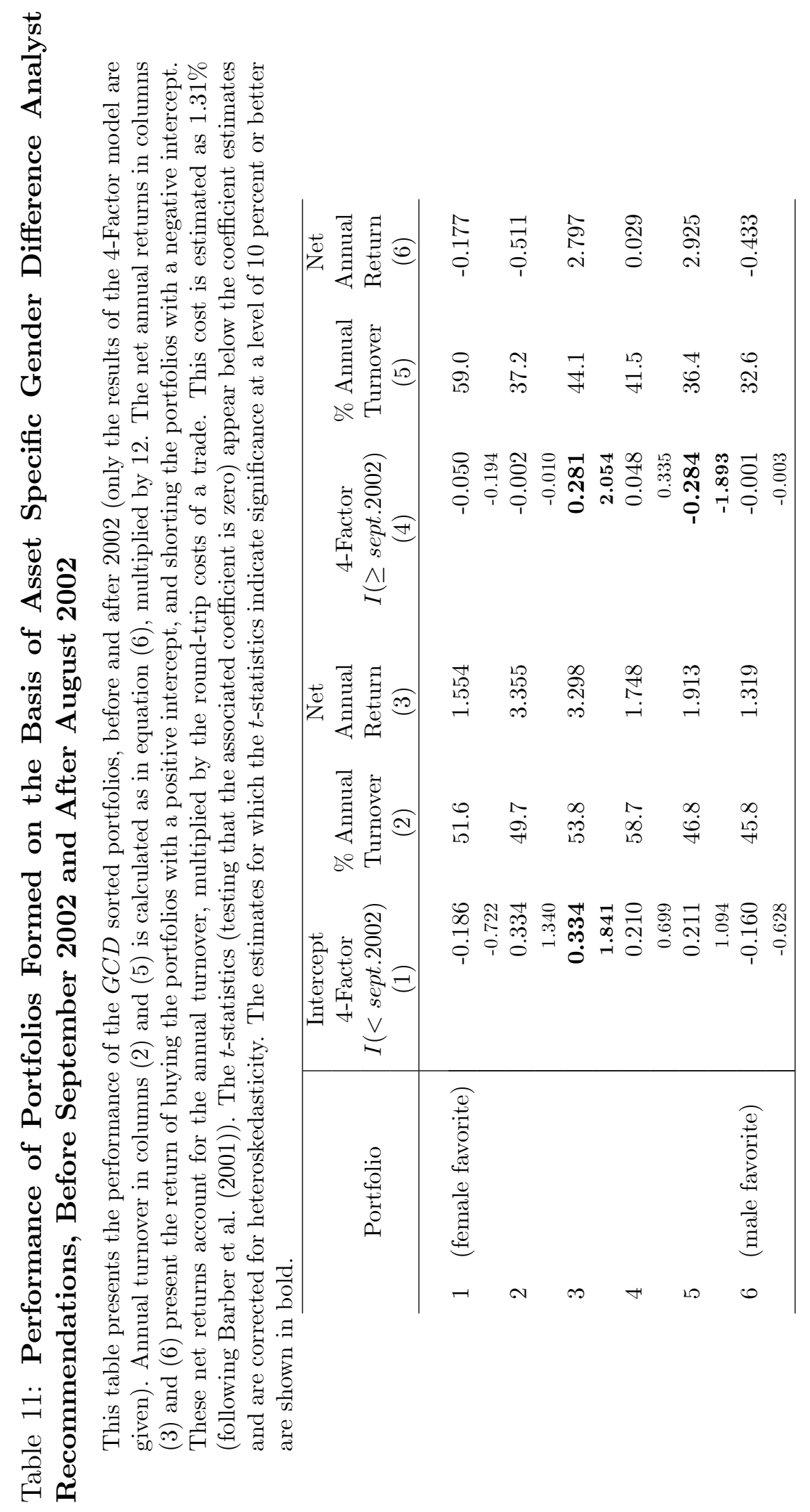




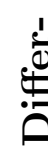

क्ष

ำㅇำ

0
0
00
0
0
0
0
0
0

कृ

¿

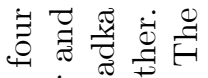

पै

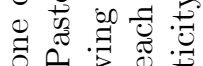

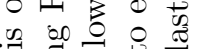

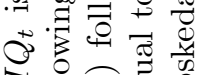

궁ㄹㅇ

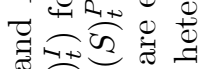

$\infty$ 可

웡․․

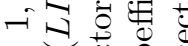

$\|=$.

2 . ํㅜㅇ

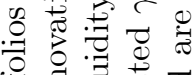

当丞芯

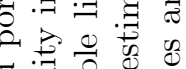

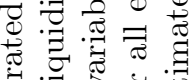

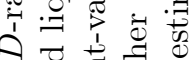

O

㱐

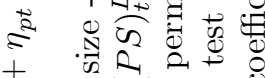

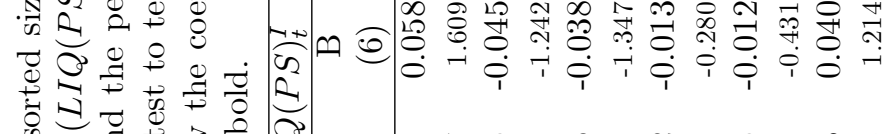

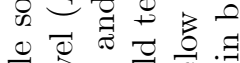

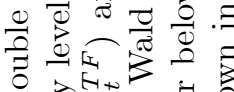

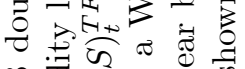

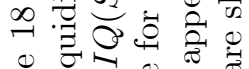

ज.

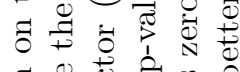

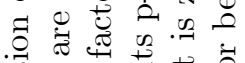

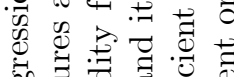

ธิ

$\rightarrow$ 范

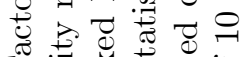

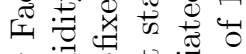

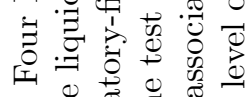

\&

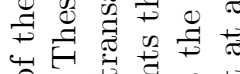

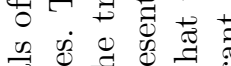

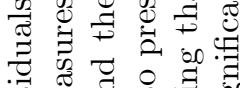

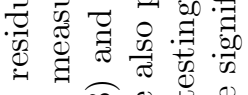

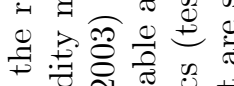

.

₹.

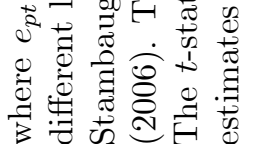

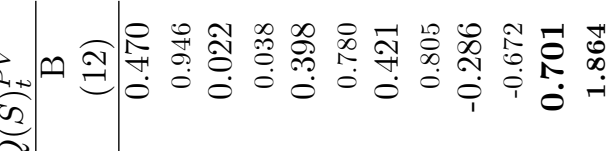

تح

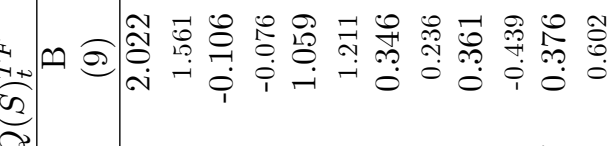

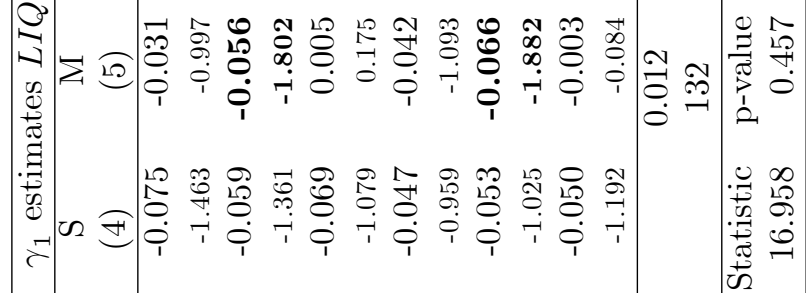

舟

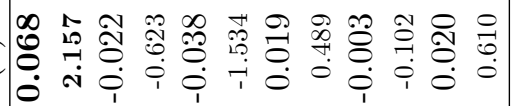

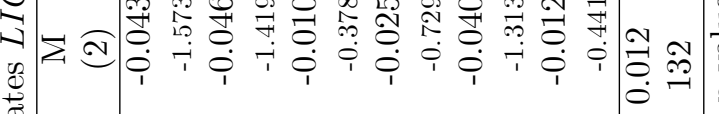

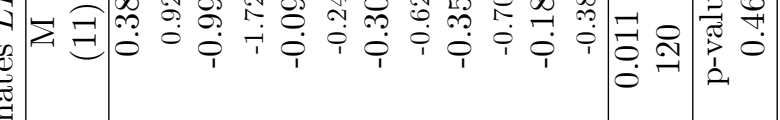

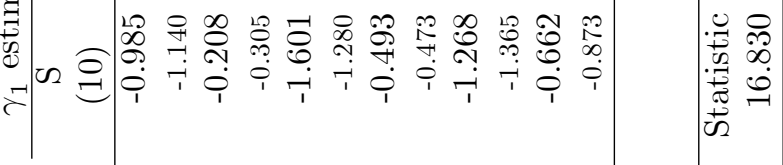

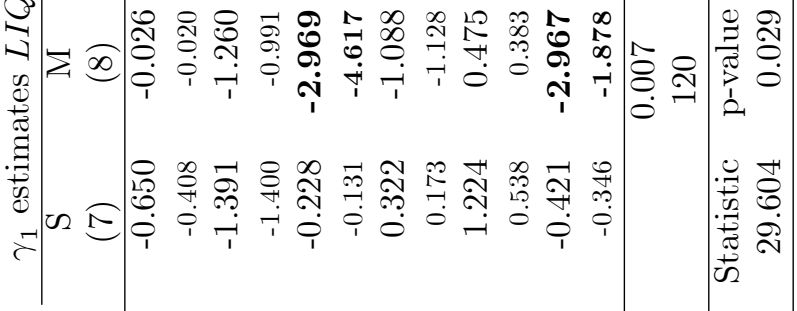

疍

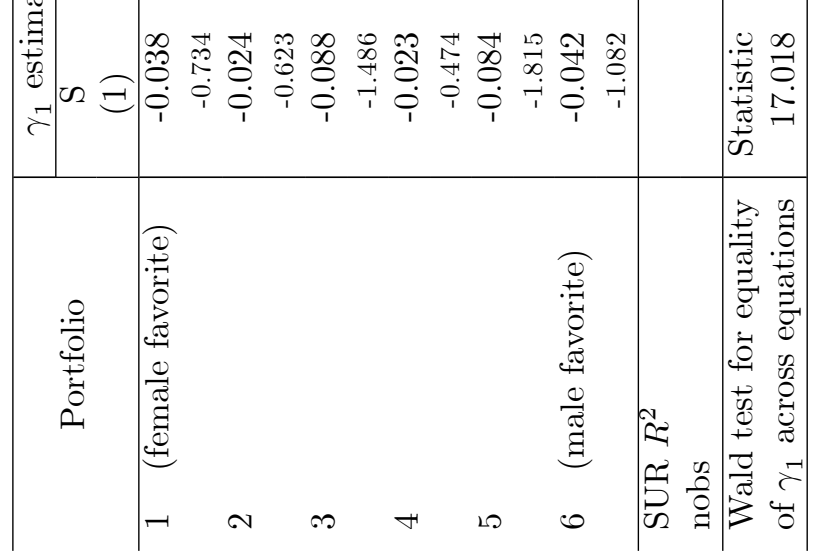




\section{Figures}
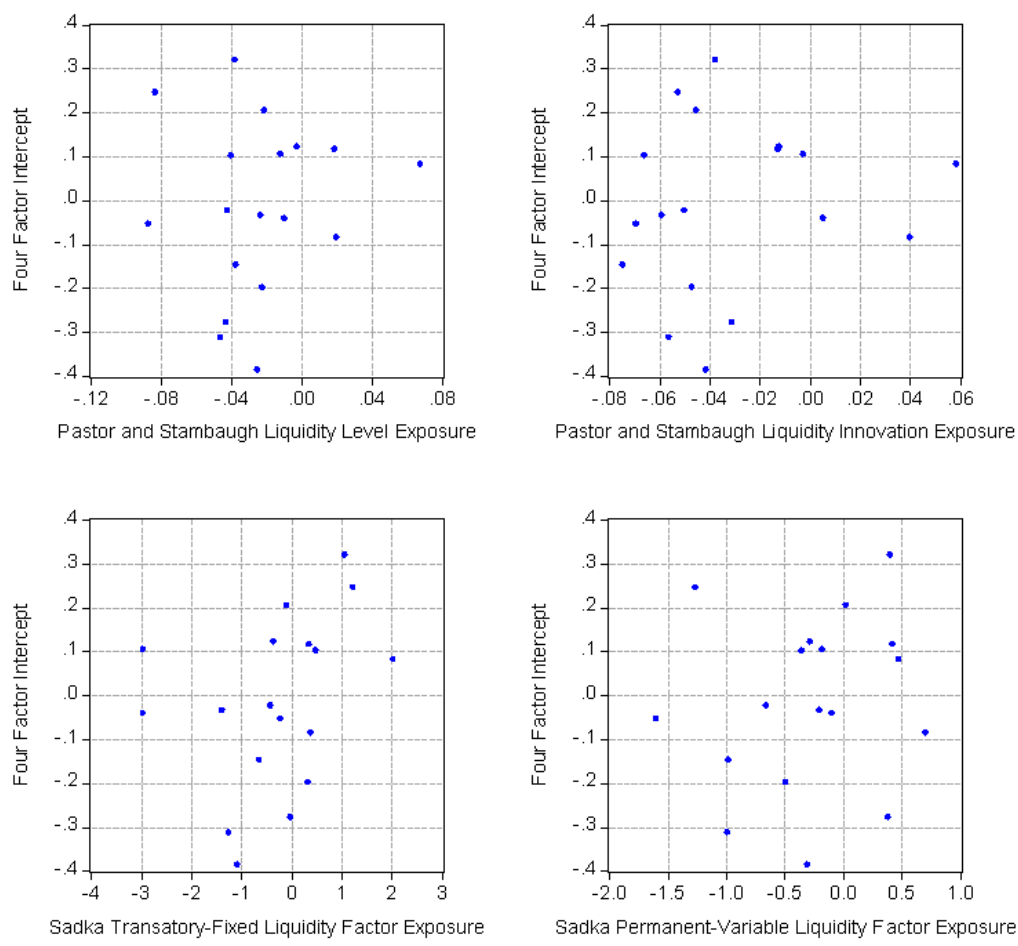

The graphs shows the relationship between estimated Jensen's alphas and the estimated liquidity exposures $\gamma_{1}$ obtained from a time-series regression of the residuals of Four Factor Model regressions using 18 portfolios that were constructed using double sorts by size and $G C D$-rating of individual assets.

Figure 1: Estimated Four Factor Intercepts versus Market Wide Liquidity Exposure 

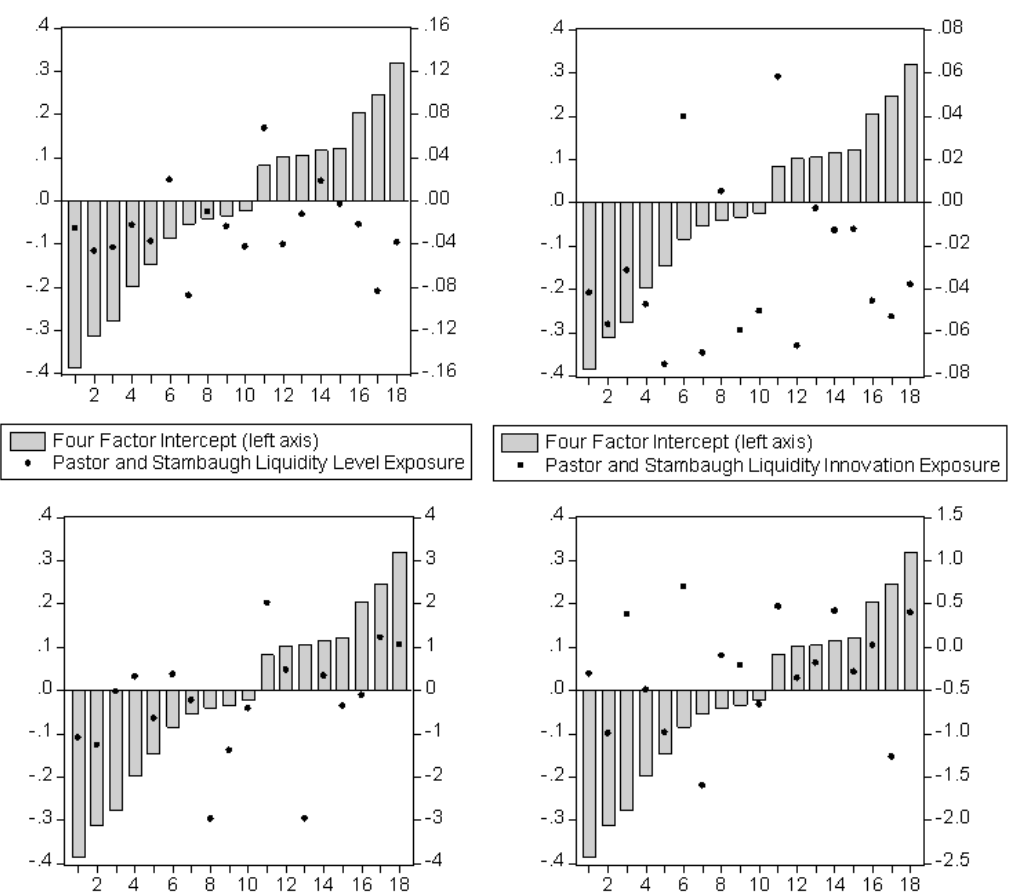

Four Factor Intercept (left axis) Sadka Transitory-Fixed Liquidity Exposure

Four Factor Intercept (left axis)

Sadka Permanent-Variable Liquidity Exposure

The graphs shows estimated Jensen's alphas together with the estimated liquidity exposures $\gamma_{1}$ obtained from a time-series regression of the residuals of Four Factor Model regressions using 18 portfolios that were constructed using double sorts by size and $G C D$-rating of individual assets. The Jensen's alphas have been sorted by size.

Figure 2: Sorted Estimated Four Factor Intercept versus Market Wide Liquidity Exposure 